\title{
A Recap of Voltage Stability Indices in the Past Three Decades
}

\author{
Mir Sayed Shah Danish 1,*(D), Tomonobu Senjyu ${ }^{2}$ (D), Sayed Mir Shah Danish ${ }^{2}$, \\ Najib Rahman Sabory ${ }^{3}$, Narayanan $K^{4}$ iD and Paras Mandal ${ }^{5}$ (D)
}

1 Strategic Research Projects Center, University of the Ryukyus, 1 Senbaru, Okinawa 903-0213, Japan

2 Department of Electrical and Electronics Engineering, University of the Ryukyus, 1 Senbaru, Okinawa 903-0213, Japan; b985542@tec.u-ryukyu.ac.jp (T.S.); sayedmir.danish@gmail.com (S.M.S.D.)

3 Department of Energy Engineering, Kabul University, Jamal Mina, Karti Sakhi, Kabul 1006, Afghanistan; najib_sabory@ku.edu.af

4 Department of Electrical and Electronics Engineering, SASTRA Deemed University, Thanjavur, Tamil Nadu 613401, India; narayanan@eee.sastra.edu

5 Department of Electrical and Computer Engineering, The University of Texas at El Paso, Texas, TX 79968, USA; pmandal@utep.edu

* Correspondence: mdanish@lab.u-ryukyu.ac.jp

Received: 23 January 2019; Accepted: 17 April 2019; Published: 24 April 2019

\begin{abstract}
Increasing demand for electricity and the modernization of power systems within competitive markets has induced power systems to operate close to their stability limits. Therefore, the continuous monitoring and control of power systems through voltage stability indices is urgently needed. This is the first-ever effort to examine more than 40 voltage stability indices based on their formulation, application, performance, and assessment measures. These indices are sorted based on a logical and chronological order considering the most recent indices to be applied worldwide. However, the generalizability of these indices in terms of multivariable objectives is limited. Despite its limitation, this study systematically reviews available indices in the literature within the past three decades to compile an integrated knowledge base with an up-to-date exposition. This is followed by a comparative analysis in terms of their similarity, functionality, applicability, formulation, merit, demerit, and overall performance. Also, a broad categorization of voltage stability indices is addressed. This study serves as an exhaustive roadmap of the issue and can be counted as a reference for planning and operation in the context of voltage stability for students, researchers, scholars, and practitioners.
\end{abstract}

Keywords: voltage stability; stability index; voltage stability indicator; power system stability; power system monitoring; voltage collapse; blackout; voltage stability classification

\section{Introduction}

Any power system is associated with a risk of blackout. The world's most tremendous blackouts due to voltage instability include the Tokyo blackout on 23 July 1987 as well as the blackouts in the United Kingdom, Sweden, Canada, Denmark, Italy, and the United States in 2003 [1,2]. In 1987, Tokyo experienced a blackout for more than 3 hours; 2.8 million consumers were affected by electricity outage [3]. Among the various reasons for blackout at different stages with various mechanisms, voltage instability is one of primary causes [4-6].

Adequate information on, and proper prediction of, the blackout phenomenon still remain critical challenges around the world. Much research has attempted to sum up blackout prediction and prevention in a power system using methodological approaches $[7,8]$. Voltage instability can supersede local-area or wide-area stability in a power system that can lead an entire system to voltage collapse. 
Therefore, a power system with continuous monitoring and instability prediction is urgently needed. Some of the many approaches in the literature reported to overcome the instability phenomenon include reactive power compensation, network loadability improvement, network re-configuration, and optimally distributed generation [9-16].

Since the 1920s, power systems stability and reliability have been continuously monitored with the help of voltage stability indices in terms of simple static to interwoven transient stability analysis [17]. Over the past three decades, various methods and mechanisms have been applied to propose tools and techniques for voltage stability analysis. The earliest methods to have been applied worldwide are singular value decomposition [18], energy function [19,20], continues power flow [21], sensitivity analysis methods [22], bifurcations theory [23], minimum eigenvalue [24], modal analysis [24,25], and integrated transmission line transfer index (ITLTI) [26]. These approaches are elucidated in the next section along with the formulation of voltage stability indices.

\section{Voltage Stability Indices}

Voltage stability indices function to situate the present operation of a power system, predict future changes to the nature of the system, and evaluate a long-run development trend within predefined circumstances. Herein, the theoretical analysis and the foundation of voltage stability indices of the first two classes (apart from the eight indices of online application) are discussed in chronological order.

\subsection{Index}

In [27], the L index is delineated with special characteristics of identification of power system vulnerability, quantitative measurement of real power, reorganization of a weak bus or area, and forecasting of voltage collapse (considering contingencies as well as generation and transmission losses) to predict instability in an electric power system. The $\mathrm{L}$ index is formulated based on a 2-bus system analytical analysis as shown in Equation (1):

$$
L=\operatorname{MAX}_{j \in \alpha_{L}}\left|1-\frac{\sum_{i \in \alpha_{G}} \bar{F}_{j i} \bar{V}_{i}}{\bar{V}_{j}}\right|
$$

where $\alpha_{L}$ is a set of consumer nodes and $\alpha_{G}$ is a set of generator nodes.

\subsection{Power Stability Index (PSI)}

In [28], the PSI is proposed to realize the optimum placement of distributed generation (DG) within a critical sensitive bus close to voltage collapse. This index is proposed based on a 2-bus system with less than the unity margin for a voltage stable operation, as given in Equation (2):

$$
P S I=\frac{4 r_{i j}\left(P_{L}-P_{G}\right)}{\left[\left|V_{i}\right| \cos (\theta-\delta)\right]^{2}} \leq 1
$$

where $r_{i j}$ is the line resistance; $P_{L}$ is the real power at the load bus; and $P_{G}$ is the injected real power of the system.

\subsection{Voltage Deviation Index (VDI)}

In [29], this index defines an absolute value of bus voltage deviation compared to 1 per unit. This index is generalized in terms of an $N$-bus system based on the sum of $N$ voltage deviations, calculated separately for each bus in all systems as given in Equation (3), and generalized in Equation (4):

$$
V D I_{j}=\left|1-V_{j}\right|
$$




$$
V D I_{T}=\sum_{j=1}^{N}\left|1-V_{j}\right|
$$

where $N$ is the number of buses under study and $V_{j}$ is the target value for index calculation.

\subsection{Stability Index (SI)}

In [30], a new index for radial distribution topology is driven by considering composite load modeling and power flow analysis. The smallest magnitude of the index at any bus indicates the most sensitive bus to voltage collapse, as given in Equation (5).

$$
|V(m 2)|=0.707\left[b(j j)+\left\{b^{2}(j j)-4.0 c(j j)\right\}^{1 / 2}\right]^{1 / 2}
$$

where $j j$ is the branch number.

After the simplification and substitution of Equation (5), the SI is given in Equation (6).

$$
S I(m 2)=\left\{|V(m 1)|^{4}-4.0\{P(m 2) x(j j)-Q(m 2) r(j j)\}\right\}^{2}-4.0\{P(m 2) r(j j)+Q(m 2) x(j j)\}|V(m 1)|^{2}
$$

\subsection{Voltage Collapse Prediction Index (VCPI)}

In [31], the VCPI is formulated to predict voltage collapse in a power system. This index is derived based on the system variables such as the bus voltage magnitude, voltage angle information, and system admittance matrix. The merit of this index is its capability to be employed in online applications (Equation (7)):

$$
V C P I_{k t h ~ b u s}=1-\frac{\sum_{m=1}^{N}\left|V_{m}^{\prime}\right|}{V_{k}}
$$

where $V_{k}$ and $V_{m}$ are the voltage phasors at bus $k$ and bus $m$. The thresholds for the VCPI are zero and 1 -An index value near to zero indicates a bus with a stable voltage. Some features of this index are highlighted as below:

- Prediction of voltage collapse in a power system for each bus.

- This index needs a modest amount of calculations for estimating the VCPI.

- This index can be used for the recognition of weak buses.

- This index can be used for both online and offline applications.

\subsection{Sensitivity Analysis (SA)}

A set of sensitivity indices is composed of various indices with different formulation approaches [32-37]. These indices measure active and reactive power changes $\left(\Delta V_{i} / \Delta Q_{i}, \Delta V_{i} / \Delta P_{i}\right)$ in a system with respect to bus voltage variation. These indices are appropriate for sensitivity analysis and weak bus identification. However, the sensitivity index alone is not sufficient for weak bus identification in an interconnected system $[9,38]$. Meanwhile, sensitivity analysis plays an important role in the prediction of critical nodes in a power system. Also, sensitivity analysis can be a useful tool for determining weak buses, active and reactive power losses, and reactive power margin (Mvar distant to voltage collapse point) [39].

\subsection{Bus Participation Factor (BPF)}

In [21,40], authors reported BPF indices based on the voltage collapse concept [41,42]. The bus participation factor is employed as one of the indicators for the identification of the weakest node in a system. 


\subsection{Voltage Stability Index (VSI)}

In [43], the VSI is driven based on system variable parameters (bus voltage and current magnitudes) to determine the distance between the current operating point and the voltage collapse point. The index is based on power flow (power transfer) equations, as given in Equation (8).

$$
V S I_{i}=\left[1+\left(\frac{I_{i}}{V_{i}}\right)\left(\frac{\Delta V_{i}}{\Delta I_{i}}\right)\right]^{\alpha}
$$

The value of the VCI is 1 at the no load condition, and zero at the voltage collapse point. This index is similar to the voltage collapse indicator with a petty difference in formulation. For the application of VSI, only magnitudes of the bus voltage and loads current at two different operating points are required. This index is transformed to the power of $(\alpha>1)$ to change in a linear fashion. The value of $\alpha$ depends on the system parameters.

\subsection{Equivalent Node Voltage Collapse Index (ENVCI)}

In [44], the ENVCI is introduced based on the equivalent system model (ESM) as given in Equation (9). This index is associated with some advantages such as affectivity from both the local network and the system outside a local network, as well as real-time application and the identification of the voltage collapse point. Also, this index can be used as a voltage collapse prediction and monitoring tool. Authors have reported the following applications of the ENVCI:

- Accuracy in index modeling; this index covers the influence of both local and outside networks.

- Analysis of internal and external impedances.

- Easy calculation with less computation time compared to the customary power flow-based methods.

Therefore, this index acts as an emergency remedial action scheme to protect a power system when it approaches the voltage collapse point.

$$
E N V C I=2\left(e_{k} e_{n}+f_{k} f_{n}\right)-\left(e_{k}^{2}+e_{k}^{2}\right)
$$

where $\theta_{k n}=\theta_{k}-\theta_{n}$; more details are given in [44].

\subsection{Voltage Collapse Index (VCI)}

As reported in [43], the VCI is formulated in Equation (10) based on a system's apparent power change using Taylor's theorem.

$$
V C I_{i}=\left[1+\left(\frac{I_{i} \Delta V_{i}}{V_{i} \Delta I_{i}}\right)\right]^{\alpha}
$$

where $V C I_{i} \geq 0$ is used to linearize the trend of the index at the collapse point.

\subsection{Improved Voltage Stability Index (IVSI)}

In [29], the IVSI is proposed to enhance the power system voltage stability. This index is formulated based on power flow variables as given in Equation (11).

$$
I V S I_{T}=\sum_{i=1}^{N} I V S I_{i}
$$

This index margin is between zero (stable operation) and 1 (unstable operation) and can be used for radial and interconnected power systems. This index aims to optimize voltage stability by the optimal setting of compensation devices for an $\mathrm{N}$-bus system. 


\subsection{Voltage Stability Factor (VSF)}

In [45], the VSF is derived from a 2-bus power flow with a threshold of zero at the collapse point, as given in Equation (12). At the collapse point, the receiving end bus voltage magnitude is equal to half that of the sending end bus voltage magnitude.

$$
V S F_{\text {total }}=\sum_{m=1}^{k-1}\left(2 V_{m+1}-V_{m}\right)
$$

where $k$ is the total number of buses in the system and $V_{m}$ is the magnitude of the substation voltage. A higher value of $V S F_{\text {total }}$ indicates a voltage stable operation.

\subsection{Line Stability Index $\left(L_{m n}\right)$}

In [46], the $L_{m n}$ index is proposed using power transfer concepts in a single line power transmission network. The proposed index is given by Equation (13):

$$
L_{m n}=\frac{4 Q r x}{\left[\left|V_{s}\right| \sin (\theta-\delta)\right]^{2}}
$$

where $V_{S}$ is the sending end voltage; $\theta$ is the line impedance angle; $\delta$ is the angle difference between the sending and receiving end voltages; $x$ is the line reactance; $Q r$ is the reactive power at the receiving end.

\subsection{Line Stability Factor ( $L Q P)$}

In [47], the LQP is proposed based on a power flow equation in a single line network as given in Equation (14):

$$
\mathrm{LQP}=4\left(\frac{X}{V_{i}^{2}}\right)\left(\frac{X}{V_{i}^{2}} P_{i}^{2}+Q_{j}\right)
$$

where $V_{i}$ is the sending end voltage; $P_{i}$ is the sending end real power; $Q_{i}$ is the receiving end reactive power; $X$ is the line reactance. For a stable operation, the LQP value must be less than 1 .

\subsection{Index}

In [48], the L weak bus identification index based on a contingency analysis of a 2-bus system is discussed (Equations (15)-(18)).

$$
L=4\left[\left(x P_{L}-r Q_{L}\right)^{2}+x Q_{L}+r P_{L}\right]
$$

For $L<1$, a generalized form of the index is given for the reduced network as below:

$$
\begin{gathered}
L=4\left[\left(x_{e g} P_{l e g}-r_{e g} Q_{l e g}\right)^{2}+x_{e g} Q_{L}+r_{e g} P_{l e g}\right] \\
r_{e g}=\frac{R_{e g}}{\left(P^{2}+Q^{2}\right)} \\
x_{e g}=\frac{X_{e g}}{\left(P^{2}+Q^{2}\right)}
\end{gathered}
$$

where $P_{L}$ and $Q_{L}$ are the real and reactive loads; $P$ and $Q$ are the injection of real and reactive power in the system; $r$ and $x$ are the line resistance and reactance; $r_{e g}$ and $x_{e g}$ are the equivalent resistance and reactance of a single line; $P_{l e g}$ and $Q_{\text {leg }}$ are the distribution network total real and reactive loads. At a critical condition (collapse point) beyond a system's loadability limit, power becomes imaginary. 


\subsection{Voltage Collapse Proximity Indicator (VCPI)}

In [49], a line index based on the maximum power transfer concept for online application is introduced. This index is derived based on a 2-bus system considering $Z_{r} / Z_{s}=1$ (the impedance ratio is lower than 1 in stable operation). A set of voltage collapse prediction indicators in view of the allowable maximum power transfer limits are given by Equations (19)-(22):

$$
\begin{aligned}
\operatorname{CPI}(1) & =\frac{P_{r}}{P_{r}(\max )} \\
\operatorname{VCPI}(2) & =\frac{Q_{r}}{Q_{r}(\max )} \\
\operatorname{VCPI}(3) & =\frac{P_{l}}{P_{l}(\max )} \\
\operatorname{VCPI}(4) & =\frac{Q_{l}}{Q_{l}(\max )}
\end{aligned}
$$

where $P_{r}$ and $Q_{r}$ are the real and reactive power transferred to the receiving end; $P_{l}$ and $Q_{l}$ are the real and reactive power losses in the line. The results show some similarity; therefore, instead of considering four indicators, either real or reactive terms can be found. In a critical situation, both power and loss indicators approach the threshold of 1 .

\subsection{Voltage Instability Proximity Index (VIPI)}

In [20], the VIPI (a quantitative index) is derived based on multiple load flow solutions to predict the voltage stability margin between operating and critical load conditions.

$$
V I P I=\theta=\cos ^{-1} \frac{Y_{s}^{T} Y(a)}{\left\|Y_{s}\right\|\|Y(a)\|}
$$

where $\theta$ is the angle between two vectors, specified values $Y_{s}$ and critical vector $Y(a) ; Y(a)$ is a critical vector in the space of node-specification.

\subsection{Integral Steady-State Margin (ISSM)}

In [20], a modified ISSM index is given to evaluate a power system at the steady-state condition. This index is preferred for planning and online security control applications.

$$
I S S M=\left|\frac{J_{c}}{J_{o}}\right|
$$

where $J_{\mathcal{c}}$ is the system steady-state Jacobian; $J_{o}$ is the system fictitious state Jacobian. The stability threshold is between zero and 1 .

\subsection{Novel Line Stability Index (NLSI)}

In [50], the NLSI is derived as shown in Equation (25). Fundamentally, it is derived from 2-bus load flow equations. The authors claimed that it is effective for point of voltage collapse, weak bus, and most critical line identification in an interconnected system.

$$
N L S I_{i j}=\frac{R_{i j} P_{j}+X_{i j} Q_{j}}{0.25 V_{i}^{2}}
$$

where $V_{i}$ is the voltage at the sending bus; $P_{j}$ and $Q_{j}$ are the active and reactive power at the receiving end bus; $R_{i j}$ and $X_{i j}$ are the line resistance and reactance between the sending and receiving end buses, respectively. 


\subsection{Fast Voltage Stability Index (FVSI)}

In [51], the FVSI is derived based on voltage collapse occurrence under a contingency condition as given by Equation (26):

$$
F V S I_{i j}=\frac{4 Z^{2} Q_{j}}{V_{i}^{2} x}
$$

where $Z$ and $x$ are the line impedance and reactance; $Q_{j}$ is the reactive power at the receiving end; $V_{i}$ is the sending end voltage. For stable operation, the magnitude of the FVSI should be less than 1.

\subsection{Critical Voltage $\left(V_{c r}\right)$}

In [52], a simple index from a single load and infinite bus power system using load flow equations and an eigenvalue theorem is derived as given in Equation (27):

$$
V_{c r}=\frac{E}{\sqrt{2(1+\cos (\alpha-\phi))}}
$$

Equation (27) can be simplified in terms of Equation (28):

$$
V_{c r}=\frac{E}{2 \cos \theta}
$$

where $V_{c r}$ is the critical voltage at the receiving end; $E$ is the infinite bus voltage; $\alpha$ is the line impedance angle; $\phi$ is the power factor angle $(P F=\cos \phi) ; \theta$ is the receiving end voltage angle.

\subsection{Power Transfer Stability Index (PTSI)}

In [53], the PTSI based on the Thevenin equivalent system of a 2-bus system is proposed as given by Equation (29):

$$
\text { PTSI }=\frac{2 S_{L} Z_{\text {Thev }}(1+\cos (\beta-\alpha))}{E_{\text {Thev }}^{2}}
$$

where $\alpha$ is the phase angle of load impedance; $\beta$ is the phase angle of the Thevenin impedance. The threshold of PTSI values is between zero and 1 (voltage collapse).

\subsection{Line Voltage Stability Index (LVSI)}

In [54], the LVSI is determined by the relationship between the line reactive power and the sending end voltage as given by Equation (30):

$$
L V S I=\frac{4 r P_{r}}{V_{S} \cos (\theta-\delta)^{2}}
$$

where $V_{s}$ is the sending end voltage; $P_{r}$ is the active power at the receiving end; $\theta$ is the line impedance angle; $\delta$ is the phase angle; $r$ is the line resistance. For a stable operation condition, the value of LVSI must satisfy $L V S I \leq 1$.

\subsection{Impedance Ration Indicator}

In [55], a voltage collapse proximity index based on the impedance ratio of a 2-bus system is proposed. This index assesses the validity and robustness of an indicator over the operating range. The Thevenin theorem is applied as given by Equations (31)-(33):

$$
\begin{gathered}
\frac{Z_{i i}}{Z_{i}} \leq 1 \\
Z_{i i}<\beta_{i}=i^{\text {th }} \text { diagonal element of }[\mathbf{Z}]
\end{gathered}
$$




$$
[\mathbf{Z}]=[\mathbf{Y}]^{-1}
$$

where $Z_{i i} \angle \beta_{i}$ is Thevenin's equivalent impedance; $Z_{i} \angle \phi_{i}$ is the impedance of the load.

\subsection{Minimum Eigenvalue and Right Eigenvector (RE) Method}

In [21], a model analysis-based index based on the smallest eigenvalue associated with the right eigenvector is proposed as expressed by Equation (34):

$$
\Delta V=\sum_{i} \frac{\xi_{i} \eta_{i}}{\lambda_{i}} \Delta Q
$$

where $\Delta V$ indicates deviation in voltage magnitudes; $\Delta Q$ indicates deviation in the injected reactive power; $\xi_{i}$ is the $i^{\text {th }}$ column right eigenvector; $\eta_{i}$ is the $i^{\text {th }}$ row left eigenvector of a reduced Jacobian matrix; $\lambda$ is the diagonal eigenvalue matrix of a reduced Jacobian matrix.

Equation (34) shows the relationship between the involved parameters as well as the effect of changes to the reactive power, eigenvalue, and eigenvectors on $\Delta V$. A system is considered voltage stable if all eigenvalues are positive. The real part of the eigenvalue indicates that the system is unstable.

\subsection{Singular Value Indicator}

In [18], a static voltage stability index based on a singular value decomposition of the power flow Jacobian matrix is formulated. This index approximates voltage instability and identifies critical nodes in a power system. Matrix $\mathbf{A}$ is supposed to be an $n \times n$ quadratic (real) matrix as given by Equation (35):

$$
\mathbf{A}=\mathbf{U} \sum \mathbf{V}^{T}=\sum_{i=1}^{n} \sigma_{i} u_{i} v_{i}^{T}
$$

where $\mathbf{U}$ and $\mathbf{V}$ are $n \times n$ orthonormal matrices; $\boldsymbol{v}_{i}$ and $\boldsymbol{u}_{i}$ are singular vectors and columns of $\mathbf{U}$ and $\mathbf{V}$ matrices; $\sum$ is a diagonal matrix given by Equation (36):

$$
\sum(\mathbf{A})=\operatorname{diag}\left\{\sigma_{i}(\mathbf{A})\right\}
$$

where $\boldsymbol{i}=1,2, \cdots, n$ and $\sigma_{i} \geq 0$ for all values of $i$.

The order of the diagonal matrix is $\sigma_{1} \geq \sigma_{2} \geq \ldots \geq \sigma_{n} \geq 0$. Considering the power flow Jacobian matrix, the result is given by Equation (37):

$$
\left[\begin{array}{c}
\Delta \theta \\
\Delta V
\end{array}\right]=\mathbf{v} \sum^{-1} \mathbf{U}^{T}\left[\begin{array}{c}
\Delta F \\
\Delta G
\end{array}\right]
$$

From the singular value decomposition of the power flow Jacobian matrix, these points are observed:

- The smallest singular value $\left(\sigma_{n}\right)$ can be used as a steady-state stability limit indicator;

- The right singular vector $\left(v_{n}\right)$ corresponding to the smallest singular value $\left(\sigma_{n}\right)$ indicates sensitive voltage and angles;

- The left singular vector $\left(u_{n}\right)$ corresponding to the smallest singular value $\left(\sigma_{n}\right)$ indicates the most sensitive direction for changes of active and reactive power injections.

\subsection{Predicting the Voltage Collapse Index $\left(V / V_{o}\right)$}

In [20], a simple $\left(V / V_{o}\right)$ index is proposed. Voltage magnitude $(V)$ is obtained from the load flow for the operating point of the system. Here, $V_{o}$ (no load voltage) is a new value at the system no load condition. This index indicates an overall picture of a power system's stability state. The smallest index value indicates the most sensitive (weak) bus in a system. This index can be used for online 
and offline applications. With respect to change in loading parameters, this index shows a nonlinear profile. In [56,57], the authors argued that the $V / V_{o}$ index is poor in terms of its computational cost, accuracy of collapse point prediction, and adequacy in nonlinear performances.

\subsection{Test Function}

In [58], the test function index is illustrated based on the quadratic shape of the proposed model. This index is reliable compared to other Jacobian matrix-based methods (eigenvalue and singular value) as given by Equation (38).

$$
t_{l k}=\left|e_{l}^{T} J J_{l k}^{-1} e_{l}\right|
$$

where $J$ is the Jacobian matrix of the system; $e_{l}$ is the $l^{t h}$ unit vector, i.e., a vector with all entries equal to zero except the $l^{\text {th }}$ row. $J_{l k}$ is defined by Equation (39):

$$
J_{l k}=\left(I-e_{l} e_{l}^{T}\right) J+e_{l} e_{k}^{T}
$$

By rearranging the Jacobian matrix with the $l^{\text {th }}$ row removed and replaced by row $e_{l}^{T}$, we can obtain the following. If $l=k=c$, the critical test function is shown as expressed by Equation (40):

$$
t_{c c}=\left|e_{c}^{T} J J_{c c}^{-1} e_{c}\right|
$$

The test function can be used to approximate voltage collapses in a system, but it is not able to identify the critical bus.

\subsection{Tangent Vector Index $\left(T V I_{i}\right)$}

In [59], the $T V I_{i}$ is derived based on the tangent vector concept and system load changes. This index directly measures the effect of load changes on the vector elements such as bus voltage magnitudes and angles. Therefore, it is a good approach to assess how a system operates far from the collapse point. This index is given by Equation (41):

$$
T V I_{i}=\left|\frac{d V_{i}}{d \lambda}\right|^{-1}
$$

where $V_{i}$ is the voltage at bus $i ; \lambda$ is the load. When the value of the derivative tends to infinity, then $T V I_{i} \rightarrow 0$.

\subsection{Second-Order Index (i Index)}

In [60], index $i$ (or the second-order index) based on the maximum singular value concept is presented to overcome the deficiencies of the previous indices. Some of the minimum singular value indices are inadequate for non-linear condition assessment. This index is considered with respect to the system total load and maximum singular value of the inverse Jacobian matrix changes, as given in Equation (42):

$$
i=\frac{1}{i_{0}} \frac{\sigma_{\max }}{d \sigma_{\max } / d \lambda_{\text {total }}}
$$

where $\sigma_{\max }$ is the maximum singular value of the Jacobian inverse matrix; $\lambda_{\text {total }}$ is the system total load; $i_{0}$ is the value of $\frac{\sigma_{\max }}{d \sigma_{\max } / d \lambda_{\text {total }}}$ at the initial operating point. The range for this index is defined as 1 under stable conditions and zero when the system tends to collapse. 


\subsection{Critical Boundary Index (CBI)}

In [61], the CBI is introduced with some novelties based on active and reactive power. This index is preferred due to its high prediction accuracy, as given in Equations (43)-(45). A transmission line is the worse-case scenario when the index is approaching zero.

$$
\begin{gathered}
C B I_{i k}=\sqrt{\Delta P_{i k}^{2}+\Delta Q_{i k}^{2}} \\
\Delta P_{i k}=X-P_{o} \\
\Delta Q_{i k}=Y-Q_{o}
\end{gathered}
$$

where $i$ is the sending end bus number and $k$ is the receiving end bus number.

\subsection{Line Voltage Stability Index (LVSI)}

In [62], the LVSI is proposed based on the methodological approach to evaluate parameter-based stability as given in Equations (46) and (47). The index threshold is between 1 and 2, with the most critical line close to the value of 1 .

$$
\begin{gathered}
L V S I=\max \left(L V S I_{j}\right) \quad \forall j=1,2,3, \ldots l \\
L V S I>1
\end{gathered}
$$

\subsection{Integrated Transmission Line Transfer Index (ITLTI)}

In [26], an integrated transmission line transfer index (ITLTI) based on radial topology is introduced (Equations (48)). This index is proposed for power transfer in a system under leading, lagging, and unity power factor conditions.

$$
P_{R}=-\frac{A V_{R}^{2}}{B} \cos (\beta-\alpha)+\frac{V_{S} V_{R}}{B} \cos (\beta-\alpha)
$$

where $P_{R}$ and $V_{R}$ are the active power and voltage at the sending end bus; $V_{S}$ is the sending end bus constant voltage; $A$ and $B$ are line parameters.

\subsection{Miscellaneous Indices}

In [63], the authors evaluated a power system operating condition beyond the collapse point. Also, in $[1,39,64]$, the authors investigated various voltage stability indices using load shedding and optimum storage technology placement techniques [65]. In [66], the authors compared three voltage stability indices, which were tested on a real power system of the Italian HV transmission grid.

\section{Voltage Stability Indices Categorization}

In Table 1, an exhaustive classification of voltage stability indices is given. 
Table 1. An exhaustive representation and classification of voltage stability indices.

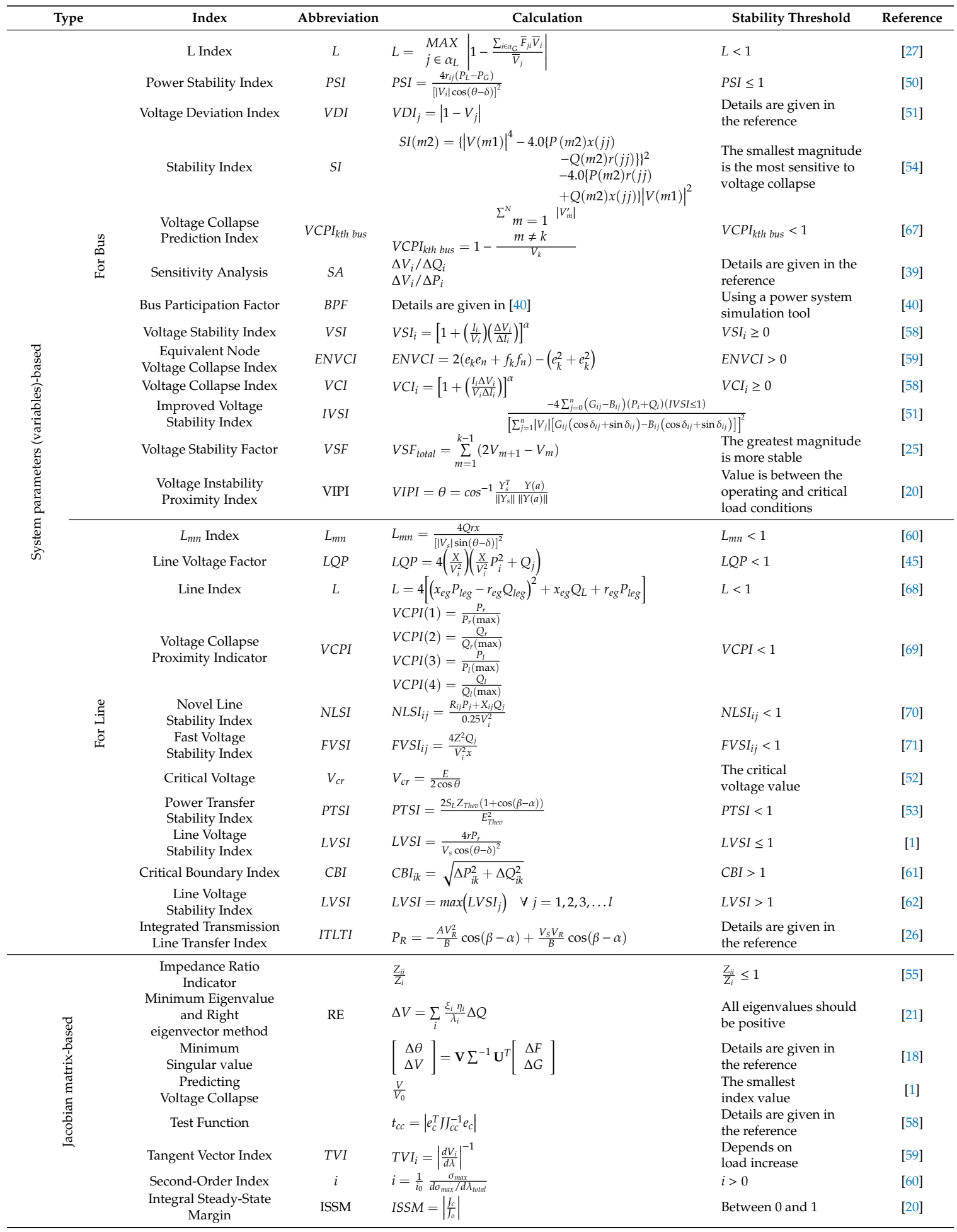


Table 1. Cont

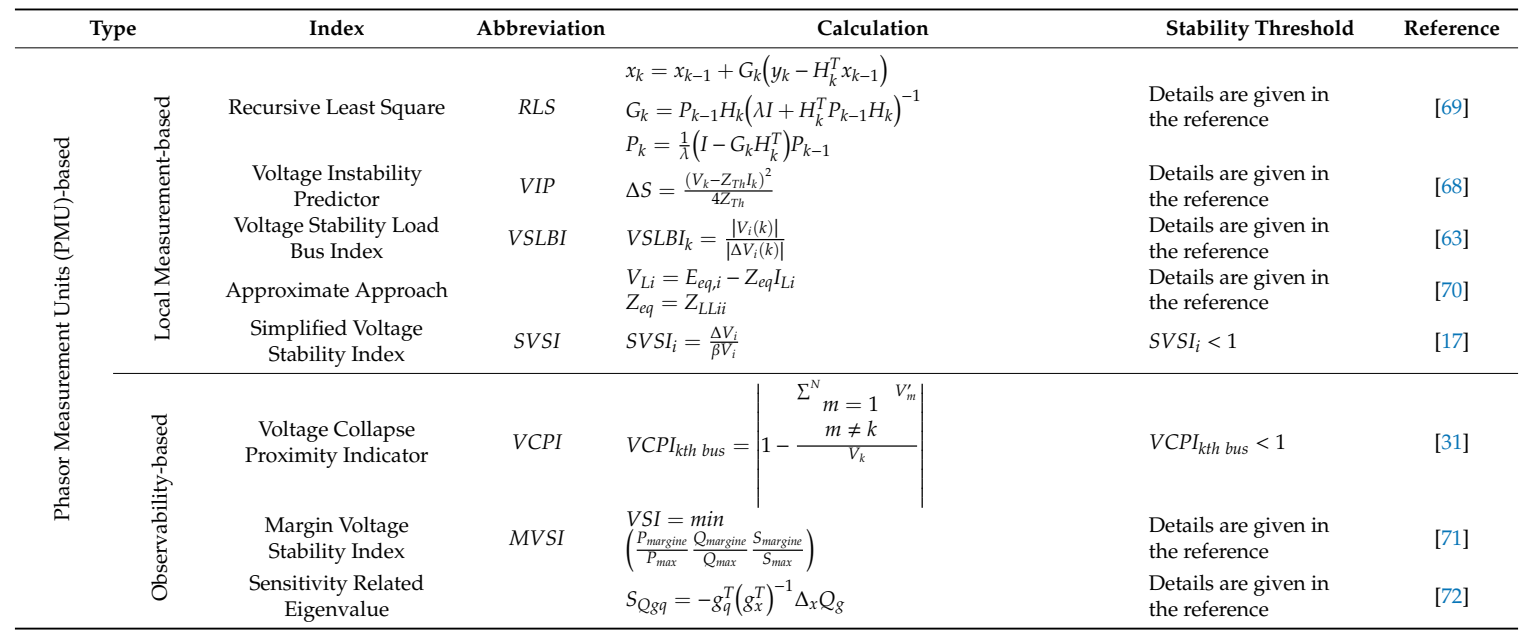

\section{Results and Discussion}

The IEEE 14-bus and 30-bus test systems [28,29] were used to evaluate a set of selected indices using the MATLAB ${ }^{\circledR}$ and PowerWorld ${ }^{\circledR}$ education and business simulation tools. Simulation results were obtained based on the indices' foundation, performance, application, merit, demerit, and overall behavior. Although the analysis and simulation of more than 40 voltage stability indices were not feasible at the same time, therefore indices were generalized in consensus groups considering their wide applicability. Also, due to the limitation of accessibility, the simulation of some indices for real-time online monitoring was ignored. Verification and testing of these indices require special hardware and software tools.

In a general sense, the simulation findings shape indices into various types for a specific application purpose. For example, bus and line indices are particularly used for sensitive-critical nodal and line identification. From an application viewpoint, voltage stability indices are distinguished based on the network topology (radial, interconnected, mesh, and so on) and operation condition. Simulation findings (Tables 2-5) present a decision-making approach to select a proper method (variable-based or Jacobian matrix-based) and an applicable index for a desired application (power transfer capability, DG optimum placement, reactive power compensation, system reinforcement, optimal load shedding, etc., for any type of topology) within a constrained limit of certainty. Apparently, all indices are in a general consensus at the first and second levels. While an index performance mainly depends on the active and reactive power changes in a system, it is also partially affected by many other influential factors. Therefore, at this stage, a particularized discussion for obvious numerical simulation results would lead to an insufficient analysis. However, the simulation findings provide a general roadmap for decision-making considering the prediction adequacy limit, type of system topology, purpose of application, and more.

Understanding the advantages and disadvantages of these indices is important because they play a significant role in power system state estimation considering voltage variation with respect to the system parameter changes. In general, singular value-based (power flow Jacobian) indices can be used for the prediction of a system's critical operating point. Additionally, this category of indices can be counted as a proper tool for instability and power transfer capability estimation under static analysis conditions. The extensive calculation time and limitations for the application of radial systems are the main disadvantages of these indices.

Sensitivity analysis-based indices employ active and reactive power changes to estimate the safety margin between a system's operation and collapse points. These indices have been demonstrated to have some limitations, such as lower accuracy of prediction in offline applications and steady-state conditions and high sensitivity in the vicinity of the critical operating point. However, these indices are 
a good tool to estimate a power system's steady-state condition with a visual graphical representation of $\mathrm{P}-\mathrm{V}$ and $\mathrm{P}-\mathrm{Q}$ curves.

It can be concluded that line indices are affected by system topology, especially in a multinetwork configuration. Some numerical zero values approach zero (0.000001) in order to overcome the power flow matrix singularity.

Based on the simulation results (Tables 2-5) and the literature, this study can be summed up as follows: Almost all indices in the same category of formulation, theoretical foundation mechanism, and application have similar accuracies and limitations. However, the performance of these indices could sometimes be in disagreement with their principle of formulation and application. Therefore, behavior-based conditional variables need to be considered for the selection of an index for monitoring or predicting the voltage stability in a power system. Performances of the VSF and PSI (nodal indices), and $V_{c r}$ (line index) are in disagreement with the rest of the indices in the same categories. These contradictory performances of indices are indicative of prediction inaccuracy at the collapse point. As such, some of these indices fail to predict the stability margin at the collapse point. Also, due to power flow limitation (singularity), most of these indices cannot predict system behavior beyond the collapse point. Meanwhile, the application of the driven indices based on a 2-bus system is associated with a factual inaccuracy concerning the interconnected topology. So, these types of indices are limited to radial and simple configurations. Therefore, employing these indices for integrated and multi-configuration systems must be done with caution. In addition to the abovementioned discussion, each index is fit for a special application scenario such as static, dynamic, semi-dynamic, or transient stability analysis [73].

Table 2. The obtained indices' magnitude for critical branch identification by each index (IEEE 14-bus system).

\begin{tabular}{|c|c|c|c|c|c|c|c|c|c|c|}
\hline \multicolumn{2}{|c|}{ Branch } & \multirow{2}{*}{ NLSI [48] } & \multicolumn{2}{|c|}{ VCPI [47] } & \multirow{2}{*}{ FVSI [49] } & \multirow{2}{*}{$L_{m n}[59]$} & \multirow{2}{*}{ LQP [45] } & \multirow{2}{*}{ L [46] } & \multirow{2}{*}{$\mathbf{V}_{\mathrm{cr}}[50]$} & \multirow{2}{*}{ LVSI [52] } \\
\hline From & To & & $\mathbf{P}$ & $\mathbf{Q}$ & & & & & & \\
\hline 1 & 2 & 0.041723 & 0.05211165 & 0.052112 & 0.029621675 & 0.031626 & 0.026752 & 0.527999 & 0.527999 & 0.097140945 \\
\hline 1 & 5 & 0.027323 & 0.053664748 & 0.053665 & 0.013449821 & 0.0129961 & 0.012704 & 0.527983 & 0.527983 & 0.651156176 \\
\hline 2 & 3 & 0.299916 & 0.603222227 & 0.603222 & 0.145540502 & 0.158298 & 0.137778 & 0.509657 & 0.509657 & 1.250791857 \\
\hline 2 & 4 & 0.076555 & 0.256248432 & 0.256248 & -0.027923844 & -0.029982 & -0.025188 & 0.514064 & 0.514064 & 0.636275 \\
\hline 2 & 5 & 0.026044 & 0.045083448 & 0.045083 & 0.0112837 & 0.0118415 & 0.010191 & 0.516391 & 0.516391 & 0.1137122 \\
\hline 3 & 4 & 0.099444 & 0.277198618 & 0.277199 & -0.030169995 & -0.029247 & -0.026155 & 0.496846 & 0.496846 & 1.187916261 \\
\hline 4 & 5 & 0.006521 & 0.011445692 & 0.011446 & 0.002863807 & 0.0028176 & 0.002602 & 0.502886 & 0.502886 & 0.051265482 \\
\hline 4 & 7 & 0 & 0 & & 0 & 0 & 0 & 0.495065 & 0.495065 & 0 \\
\hline 4 & 9 & 0.356591 & 0.627703555 & 0.627704 & 0.356590282 & 0.3589291 & 0.35659 & 0.491635 & 0.491635 & 0.000174855 \\
\hline 5 & 6 & 0.07274 & 0.115325447 & 0.115325 & 0.072739998 & 0.0734022 & 0.07274 & 0.494136 & 0.494136 & 4.77773E-05 \\
\hline 6 & 11 & 0.024123 & 0.028720079 & 0.02872 & 0.015360637 & 0.0155092 & 0.012508 & 0.517274 & 0.517274 & 0.060026116 \\
\hline 6 & 12 & 0.040494 & 0.056754618 & 0.056755 & 0.01760098 & 0.0178617 & 0.0143 & 0.516576 & 0.516576 & 0.131357137 \\
\hline 6 & 13 & 0.057598 & 0.070516198 & 0.070516 & 0.03320431 & 0.0337737 & 0.026398 & 0.516382 & 0.516382 & 0.14285981 \\
\hline 7 & 8 & 0 & 0 & & 0 & 0 & 0 & 0.516396 & 0.516396 & 0 \\
\hline 7 & 9 & 0.064826 & 0.114111626 & 0.114112 & 0.064825202 & 0.0648746 & 0.064825 & 0.512818 & 0.512818 & 0.001376514 \\
\hline 9 & 10 & 0.027853 & 0.032929845 & 0.03293 & 0.020073907 & 0.0201163 & 0.017582 & 0.509736 & 0.509736 & 0.081531112 \\
\hline 9 & 14 & 0.116444 & 0.154906644 & 0.154907 & 0.059217931 & 0.0603135 & 0.048499 & 0.507436 & 0.507436 & 0.346865422 \\
\hline 10 & 11 & 0.022919 & 0.028003345 & 0.028003 & 0.014804447 & 0.0147367 & 0.01252 & 0.508084 & 0.508084 & 0.069127813 \\
\hline 12 & 13 & 0.148792 & 0.15512846 & 0.155128 & 0.092525866 & 0.0928123 & 0.041648 & 0.509234 & 0.509234 & 0.194360274 \\
\hline 13 & 14 & 0.155423 & 0.203896609 & 0.203897 & 0.078305626 & 0.0795052 & 0.063087 & 0.504769 & 0.504769 & 0.447143333 \\
\hline
\end{tabular}


Table 3. The obtained indices' magnitude for critical branch identification by each index (IEEE 30-bus system).

\begin{tabular}{|c|c|c|c|c|c|c|c|c|c|c|}
\hline \multicolumn{2}{|c|}{ Branch } & \multirow{2}{*}{ NLSI [48] } & \multicolumn{2}{|c|}{ VCPI [47] } & \multirow{2}{*}{ FVSI [49] } & \multirow{2}{*}{$L_{m n}[59]$} & \multirow{2}{*}{ LQP [45] } & \multirow{2}{*}{ L [46] } & \multirow{2}{*}{$\mathrm{V}_{\mathrm{cr}}[50]$} & \multirow{2}{*}{ LVSI [52] } \\
\hline From & To & & $\mathbf{P}$ & $\mathbf{Q}$ & & & & & & \\
\hline 1 & 2 & 0.040829 & 0.050792427 & 0.050792 & 0.028895385 & 0.0310744 & 0.025997 & 0.098337212 & 0.52767 & 0.090772386 \\
\hline 1 & 3 & 0.010919 & 0.014938477 & 0.014938 & 0.007585635 & 0.0083082 & 0.007057 & 0.012527058 & 0.52543 & 0.025650757 \\
\hline 2 & 4 & 0.026048 & 0.045052501 & 0.045053 & 0.011276206 & 0.0118532 & 0.01018 & 0.028476133 & 0.51566 & 0.112409942 \\
\hline 2 & 5 & 0.30087 & 0.604439542 & 0.60444 & 0.145826669 & 0.160899 & 0.138008 & 0.328598596 & 0.50665 & 1.144735735 \\
\hline 2 & 6 & 0 & 0 & 0 & 0 & 0 & 0 & 0 & 0.5128 & 0 \\
\hline 3 & 4 & 0.006176 & 0.01041434 & 0.010414 & 0.002609098 & 0.002668 & 0.002327 & 0.007126896 & 0.50382 & 0.03010354 \\
\hline 4 & 6 & 0 & 0 & 0 & 0 & 0 & 0 & 0 & 0.49661 & 0 \\
\hline 4 & 12 & 0.07499 & 0.118891841 & 0.118892 & 0.074989455 & 0.0757245 & 0.074989 & 0.085385582 & 0.48891 & 4.50637E-05 \\
\hline 5 & 7 & 0.090705 & 0.115125046 & 0.115125 & 0.057375984 & 0.0563883 & 0.049579 & 0.119787331 & 0.49235 & 0.340584256 \\
\hline 6 & 7 & 0.058802 & 0.07838679 & 0.078387 & 0.0386867 & 0.0395283 & 0.034978 & 0.09272165 & 0.49284 & 0.206965597 \\
\hline 6 & 8 & 0.063398 & 0.0702055 & 0.070206 & 0.053334474 & 0.0537404 & 0.049309 & 0.39519504 & 0.49482 & 0.170861069 \\
\hline 6 & 9 & 0 & 0 & 0 & 0 & 0 & 0 & 0 & 0.49027 & 0 \\
\hline 6 & 10 & 0.043518 & 0.108695808 & 0.108696 & 0.043517353 & 9.9869167 & 0.043517 & 0.045080286 & 0.06397 & 2.27972E-07 \\
\hline 6 & 28 & 0 & 0 & 0 & 0 & 0 & 0 & 0 & 0.49504 & 0 \\
\hline 8 & 28 & 0 & 0 & 0 & 0 & 0 & 0 & 0 & 0.49455 & 0 \\
\hline 9 & 10 & 0.007967 & 0.019898883 & 0.019899 & 0.007966678 & 0.5637133 & 0.007967 & 0.00954225 & 0.0665 & 2.13041E-07 \\
\hline 9 & 11 & 0 & 0 & 0 & 0 & 0 & 0 & 0 & 0.50967 & 0 \\
\hline 10 & 17 & 0.028633 & 0.033734145 & 0.033734 & 0.02059127 & 0.0737685 & 0.017952 & 0.041426624 & 0.50263 & 0.01411637 \\
\hline 10 & 20 & 0.012902 & 0.01767585 & 0.017676 & 0.00643366 & 0.0065182 & 0.005359 & 0.014111878 & 0.50097 & 0.04240821 \\
\hline 10 & 21 & 0.053035 & 0.060349918 & 0.06035 & 0.037360687 & 0.0376328 & 0.030728 & 0.097034106 & 0.50193 & 0.121570373 \\
\hline 10 & 22 & 0 & 0 & 0 & 0 & 0 & 0 & 0 & 0.50197 & 0 \\
\hline 12 & 13 & 0 & 0 & & 0 & 0 & 0 & 0 & 0.51065 & 0 \\
\hline 12 & 14 & 0.041984 & 0.059037913 & 0.059038 & 0.018051019 & 0.0183289 & 0.014659 & 0.046906472 & 0.50847 & 0.136465701 \\
\hline 12 & 15 & 0.031106 & 0.041296468 & 0.041296 & 0.014679599 & 0.0149431 & 0.011672 & 0.035572384 & 0.50824 & 0.088769537 \\
\hline 12 & 16 & 0.024647 & 0.02937138 & 0.029371 & 0.015701355 & 0.0158558 & 0.012805 & 0.028024412 & 0.50924 & 0.061544138 \\
\hline 14 & 15 & 0.084992 & 0.09163833 & 0.091638 & 0.040839478 & 0.0409835 & 0.018357 & 0.092755535 & 0.50151 & 0.120696655 \\
\hline 15 & 18 & 0.020048 & 0.027428989 & 0.027429 & 0.009061192 & 0.0091584 & 0.007301 & 0.021616528 & 0.49755 & 0.062840994 \\
\hline 15 & 23 & 0.023879 & 0.028382608 & 0.028383 & 0.014939354 & 0.0150415 & 0.011999 & 0.026091741 & 0.49812 & 0.058727501 \\
\hline 16 & 17 & 0.058128 & 0.072986174 & 0.072986 & 0.043887473 & 0.0440292 & 0.040854 & 0.070101281 & 0.50263 & 0.239539698 \\
\hline 18 & 19 & 0.039604 & 0.051041895 & 0.051042 & 0.020694215 & 0.0207567 & 0.016627 & 0.043741276 & 0.49231 & 0.115489427 \\
\hline 19 & 20 & 0.004651 & 0.006144183 & 0.006144 & 0.002260905 & 0.0022532 & 0.001809 & 0.005017176 & 0.49186 & 0.014409058 \\
\hline 21 & 22 & 0 & 0 & & 0 & 0 & 0 & 0 & 0.4962 & 0 \\
\hline 22 & 24 & 0.0823 & 0.086120355 & 0.08612 & 0.06338884 & 0.0639164 & 0.044869 & 0.098570945 & 0.49575 & 0.125606794 \\
\hline 23 & 24 & 0.112158 & 0.121864537 & 0.121865 & 0.085002814 & 0.0852595 & 0.068605 & 0.12586848 & 0.4924 & 0.222962198 \\
\hline 24 & 25 & 0 & 0 & & 0 & 0 & 0 & 0 & 0.49107 & 0 \\
\hline 25 & 26 & 0.068102 & 0.072452792 & 0.072453 & 0.048854314 & 0.0493389 & 0.033735 & 0.07095236 & 0.4881 & 0.108666623 \\
\hline 25 & 27 & 0 & 0 & & 0 & 0 & 0 & 0 & 0.49042 & 0 \\
\hline 28 & 27 & 0 & 0 & & 0 & 0 & 0 & 0 & 0.48512 & 0 \\
\hline 27 & 29 & 0.034381 & 0.042956211 & 0.042956 & 0.018252083 & 0.0186823 & 0.014258 & 0.036055342 & 0.49025 & 0.084977094 \\
\hline 27 & 30 & 0.173159 & 0.252141728 & 0.252142 & 0.056013018 & 0.0583534 & 0.043683 & 0.189629084 & 0.48792 & 0.515014545 \\
\hline 29 & 30 & 0.135086 & 0.197026775 & 0.197027 & 0.043749241 & 0.0444823 & 0.034177 & 0.139543964 & 0.47839 & 0.435559311 \\
\hline
\end{tabular}

Table 4. The obtained indices' magnitude for weak bus identification by each index (IEEE 14-bus system).

\begin{tabular}{|c|c|c|c|c|c|c|c|c|}
\hline \multirow{2}{*}{ Bus } & \multicolumn{2}{|c|}{ Branch } & \multirow{2}{*}{ VSF } & \multirow{2}{*}{ PSI } & \multirow{2}{*}{$\mathrm{Vj} / \mathrm{Vo}$} & \multirow{2}{*}{ BPF } & \multirow{2}{*}{ RE } & \multirow{2}{*}{$S$} \\
\hline & From & To & & & & & & \\
\hline \multirow{3}{*}{4} & 2 & 4 & 1.080872 & 1.93368064 & 0.94908 & \multirow{3}{*}{0.0139} & \multirow{3}{*}{0.119854} & \multirow{3}{*}{0.044} \\
\hline & 3 & 4 & 1.004157 & 5.533106601 & 0.94908 & & & \\
\hline & 1 & 5 & 1.107938 & 0.263729008 & 0.954419 & & & \\
\hline \multirow[t]{2}{*}{5} & 2 & 5 & 1.074834 & 0.306090238 & 0.954419 & \multirow[t]{2}{*}{0.0064} & \multirow[t]{2}{*}{0.080149} & \multirow[t]{2}{*}{0.0427} \\
\hline & 4 & 5 & 1.016568 & 0.244039621 & 0.954419 & & & \\
\hline 7 & 4 & 7 & 0.976958 & 0 & 0.949303 & 0.1616 & 0.401572 & 0.1417 \\
\hline \multirow[b]{2}{*}{9} & 4 & 9 & 0.986545 & $3.55711 \mathrm{E}-05$ & 0.929802 & \multirow[b]{2}{*}{0.2256} & \multirow{2}{*}{0.476716} & \multirow{2}{*}{0.1377} \\
\hline & 7 & 9 & 1.067908 & $1.96145 \mathrm{E}-05$ & 0.929802 & & & \\
\hline 10 & 9 & 10 & 1.060878 & 1.045255773 & 0.925681 & 0.2333 & 0.48392 & 0.1621 \\
\hline \multirow{2}{*}{11} & 6 & 11 & 1.083193 & 0.302194356 & 0.93142 & \multirow{2}{*}{0.93142} & \multirow{2}{*}{0.0926} & \multirow{2}{*}{0.48392} \\
\hline & 10 & 11 & 1.045101 & 0.532718621 & 0.93142 & & & \\
\hline 12 & 6 & 12 & 1.085044 & 0.665506183 & 0.930355 & 0.0095 & 0.096489 & 0.1377 \\
\hline \multirow[b]{2}{*}{13} & 6 & 13 & 1.089898 & 0.645425171 & 0.926024 & \multirow{2}{*}{0.0198} & \multirow{2}{*}{0.138994} & \multirow[b]{2}{*}{0.0872} \\
\hline & 12 & 13 & 1.060002 & 0.36546909 & 0.926024 & & & \\
\hline \multirow{2}{*}{14} & 9 & 14 & 1.076698 & 2.150384317 & 0.912321 & \multirow{2}{*}{0.2374} & \multirow{2}{*}{0.48619} & \multirow{2}{*}{0.2233} \\
\hline & 13 & 14 & 1.065465 & 2.537073855 & 0.912321 & & & \\
\hline
\end{tabular}


Table 5. The obtained indices' magnitude for three weakest buses identification by each index (IEEE 30-bus system).

\begin{tabular}{ccccccccc}
\hline Bus & From & To & VSF & PSI & Vj/Vo & BPF & RE & S \\
\hline 26 & 25 & 26 & 1.036053 & 0.369924625 & 0.93985 & 0.174031 & 0.414541 & 0.7299 \\
29 & 27 & 29 & 1.044453 & 0.439171371 & 0.945386 & 0.157802 & 0.399068 & 0.6733 \\
30 & 29 & 30 & 1.016233 & 2.707961113 & 0.934087 & 0.156804 & 0.394602 & 0.6024 \\
\hline
\end{tabular}

\section{Conclusions}

This is the first-ever research effort that virtually delineates almost 40 voltage stability indices over the past three decades. This study provides a detailed exposition of the indices' foundation, formulation, performance behavior, optimal application, and effectuation approaches in terms of their advantages and disadvantages within specific circumstances. Also, with an in-depth review of the literature, a comprehensive categorization of most-used indices worldwide is given. This classification can be counted as a novel framework for voltage stability. Moreover, this research evaluates the emerging role of stability assessment in power systems. Finally, this study exposes a brief thesis on inconsistency among voltage stability indices due to discrepancies in their behaviors. These divergences lead to somewhat contradictory results for specific applications. Hence, this paper makes several contributions to the current literature. Overall, it can be counted as a resource of information for researchers, scholars, operators, and engineers in the context of power system voltage stability monitoring and instability prediction and prevention.

Author Contributions: Conceptualization, M.S.S.D. and T.S.; Methodology, M.S.S.D. and N.R.S.; Software, S.M.S.D.; Validation, N.K., S.M.S.D., and P.M.; Formal analysis, S.M.S.D.; investigation, M.S.S.D.; Resources, N.R.S.; data curation, S.M.S.D.; Writing_original draft preparation, M.S.S.D.; Writing—review and editing, M.S.S.D., N.K., and T.S.; Visualization, M.S.S.D.; Supervision, T.S.; Project administration, M.S.S.D., N.K., and P.M.; Funding acquisition, M.S.S.D. and T.S.

Funding: This research was funded by the Strategic Research Projects Center, University of the Ryukyus grant number (98394640).

Conflicts of Interest: The authors declare no conflict of interest.

\section{References}

1. Danish, M.S.S. Voltage Stability in Electric Power System: A Practical Introduction, 1st ed.; Logos Verlag Berlin GmbH: Berlin, Germany, 2015; ISBN 978-3-8325-3878-1.

2. Final Report on the August 14, 2003 Blackout in the United States and Canada: Causes and Recommendations. Available online: https://www.osti.gov/etdeweb/biblio/20461178 (accessed on 23 April 2019).

3. Ohno, T.; Imai, S. The 1987 Tokyo blackout. In Proceedings of the 2006 IEEE PES Power Systems Conference and Exposition, Atlanta, GA, USA, 29 October-1 November 2006; pp. 314-318.

4. Kurita, A.; Sakuraj, T. The power system failure on July 23, 1987 in Tokyo. In Proceedings of the Proceedings of the 27th IEEE Conference on Decision and Control, Austin, TX, USA, 7-9 December 1988; pp. 2093-2097.

5. Xue, Y. Towards space-time cooperative defence framework against blackouts in China. In Proceedings of the 2007 IEEE Power Engineering Society General Meeting, Tampa, FL, USA, 24-28 June 2007; pp. 1-6.

6. Xie, D.; Hui, H.; Ding, Y.; Lin, Z. Operating reserve capacity evaluation of aggregated heterogeneous TCLs with price signals. Appl. Energy 2018, 216, 338-347. [CrossRef]

7. Blackouts, P.W. A three-stage procedure for controlled islanding to prevent wide-area blackouts. Energies 2018, 11, 1-15.

8. Han, C.; Zhao, Y.; Lin, Z.; Ding, Y.; Yang, L.; Lin, G.; Mo, T.; Ye, X. Critical lines identification for skeleton-network of power systems under extreme weather conditions based on the modified VIKOR method. Energies 2018, 11, 1355. [CrossRef]

9. Danish, M.S.S.; Yona, A.; Senjyu, T. Optimum Loadability Improvement of Weak Buses using Shunt Capacitors to Enhance Voltage Stability Margin. In Proceedings of the International Conference on Engineering and Applied Science (ICEAS), Higher Education Forum (HEF), Tokyo, Japan, 15-17 March 2013; Volume 1, pp. 1063-1069. 
10. Su, H.-Y.; Chen, Y.-C.; Hsu, Y.-L. A synchrophasor based optimal voltage control scheme with successive voltage stability margin improvement. Appl. Sci. 2016, 6, 14. [CrossRef]

11. Warid, W.; Hizam, H.; Mariun, N.; Abdul-Wahab, N.; Warid, W.; Hizam, H.; Mariun, N.; Abdul-Wahab, N.I. Optimal power flow using the Jaya algorithm warid. Energies 2016, 9, 678. [CrossRef]

12. Lee, Y.; Song, H. A reactive power compensation strategy for voltage stability challenges in the Korean power system with dynamic loads. Sustainability 2019, 11, 326. [CrossRef]

13. Inkollu, S.R.; Kota, V.R. Optimal setting of FACTS devices for voltage stability improvement using PSO adaptive GSA hybrid algorithm. Eng. Sci. Technol. Int. J. 2016, 19, 1166-1176.

14. Vahid-Pakdel, M.J.; Seyedi, H.; Mohammadi-Ivatloo, B. Enhancement of power system voltage stability in multi-carrier energy systems. Int. J. Electr. Power Energy Syst. 2018, 99, 344-354. [CrossRef]

15. Ingole, D.A.; Gohokar, V.N. Voltage stability improvement in multi-bus system using static synchronous series compensator. Eenrgy Procedia 2011, 117, 999-1006. [CrossRef]

16. Berizzi, A.; Marannino, P.; Merlo, M.; Pozzi, M.; Zanellini, F. Steady-state and dynamic approaches for the evaluation of loadability margins in the presence of secondary voltage regulation. IEEE Trans. Power Syst. 2004, 19, 1048-1057. [CrossRef]

17. Pérez-londoño, S.; Rodríguez, L.F.; Olivar, G. A simplified voltage stability index (SVSI). Electr. Power Energy Syst. 2014, 63, 806-813. [CrossRef]

18. Andersson, G.; Hill, J. Voltage stability indices for stressed power systems. IEEE Trans. Power Syst. 1993, 8 , 326-335.

19. Cifci, A.; Uyaroglu, Y.; Yalcin, M.A. Voltage stability via energy function analysis on reduced order model of power system. Turk. J. Electr. Eng. Comput. Sci. 2012, 20, 1031-1043.

20. Van Hecke, J.; Hatziargyriou, N.D.; Van Cutsem, T. Indices Predicting Voltage Collapse Including Dynamic Phenomena 91; CIGRE: Paris, France, 1994; pp. 1-94.

21. Gao, B.; Morison, G.K.; Kundur, P. Voltage stability evaluation using modal analysis. IEEE Trans. Power Syst. 1992, 7, 1529-1542. [CrossRef]

22. Overbye, T.J.; Demarco, C.L. Improved techniques for power system voltage stability assessment using energy methods. IEEE Trans. Power Syst. 1991, 6, 1446-1452. [CrossRef]

23. Eady, S.I.; Christy, C. The continuation power flow: a tool for steady state voltage stability analysis. IEEE Trans. Power Syst. 1992, 7, 416-423.

24. Kundur, P.; Paserba, J.; Ajjarapu, V.; Andersson, G.; Bose, A.; Canizares, C.; Hatziargyriou, N.; Hill, D.; Stankovic, A.; Carson, T.; et al. Definition and classification of power system stability IEEE/CIGRE joint task force on stability terms and definitions. IEEE Trans. Power Syst. 2004, 19, 1387-1401.

25. Kayal, P.; Chanda, C.K. Placement of wind and solar based DGs in distribution system for power loss minimization and voltage stability improvement. Int. J. Electr. Power Energy Syst. 2013, 53, 795-809. [CrossRef]

26. Chuang, S.J.; Hong, C.M.; Chen, C.H. Improvement of integrated transmission line transfer index for power system voltage stability. Int. J. Electr. Power Energy Syst. 2016, 78, 830-836. [CrossRef]

27. Kessel, P.; Glavitsch, H. Estimating the Voltage Stability of a Power System. IEEE Trans. Power Deliv. 1986, 1, 346-354. [CrossRef]

28. Aman, M.M.; Jasmon, G.B.; Mokhlis, H.; Bakar, A.H.A. Optimal placement and sizing of a DG based on a new power stability index and line losses. Int. J. Electr. Power Energy Syst. 2012, 43, 1296-1304. [CrossRef]

29. Yang, C.F.; Lai, G.G.; Lee, C.H.; Su, C.T.; Chang, G.W. Optimal setting of reactive compensation devices with an improved voltage stability index for voltage stability enhancement. Int. J. Electr. Power Energy Syst. 2012, 37, 50-57. [CrossRef]

30. Chakravorty, M.; Das, D. Voltage stability analysis of radial distribution networks. Int. J. Electr. Power Energy Syst. Energy Syst. 2012, 23, 129-135. [CrossRef]

31. Balamourougan, V.; Sidhu, T.S.; Sachdev, M.S. Technique for online prediction of voltage collapse. IEE Proc. Gen. Transm. Distrib. IET 2009, 151, 453-460. [CrossRef]

32. Chen, H.; Jiang, T.; Yuan, H.; Jia, H.; Bai, L.; Li, F. Wide-area measurement-based voltage stability sensitivity and its application in voltage control. Int. J. Electr. Power Energy Syst. 2017, 88, 87-98. [CrossRef]

33. Li, H.; Zhou, L.; Mao, M.; Zhang, Q. Three-layer voltage/Var control strategy for PV cluster considering steady-state voltage stability. J. Clean. Prod. 2019, 217, 56-58. [CrossRef] 
34. Tang, L.; Mccalley, J. Quantitative transient voltage dip assessment of contingencies using trajectory sensitivities. Electr. Power Energy Syst. 2014, 61, 298-304. [CrossRef]

35. Xiao, Y.; Wang, Y. Reactive power optimal control of a wind farm for minimizing collector system losses. Energies 2018, 11, 3177. [CrossRef]

36. Hai, T.P.; Cho, H.; Chung, I.Y.; Kang, H.K.; Cho, J.; Kim, J. A novel voltage control scheme for low-voltage DC distribution systems using multi-agent systems. Energies 2017, 10, 41. [CrossRef]

37. Ghaffarianfar, M.; Hajizadeh, A. Voltage Stability of Low-Voltage Distribution Grid with High Penetration of Photovoltaic Power Units. Eenergies 2018, 11, 1960. [CrossRef]

38. Danish, M.S.S.; Yona, A.; Senjyu, T. Voltage stability assessment index for recognition of proper bus for load shedding. In Proceedings of the 2014 International Conference on Information Science, Electronics and Electrical Engineering (ISEEE 2014), Sapporo City, Hokkaido, Japan, 26-28 April 2014; Volume 1, pp. 636-639.

39. Ajjarapu, V. Computational Techniques for Voltage Stability Assessment and Control, 1st ed.; Springer International Publishing: Cham, Switzerland, 2007; ISBN 978-0-387-26080-8.

40. Reis, C.; Barbosa, F.P.M. A comparison of voltage stability indices. In Proceedings of the 2006 IEEE Mediterranean Electrotechnical Conference (MELECON 2006), Valletta, Malta, 26-28 April 2006; pp. 1007-1010.

41. Vassilyev, S.N.; Yadykin, I.B.; Iskakov, A.B.; Kataev, D.E.; Grobovoy, A.A.; Kiryanova, N.G. Participation factors and sub-Gramians in the selective modal analysis of electric power systems. IFAC Pap. 2017, 50, 14806-14811. [CrossRef]

42. Song, Y.; Hill, D.J.; Liu, T. State-in-mode analysis of the power flow Jacobian for static voltage stability. Int. J. Electr. Power Energy Syst. 2019, 105, 671-678. [CrossRef]

43. Haque, M.H. Use of local information to determine the distance to voltage collapse. In Proceedings of the International Power Engineering Conference (IPEC 2007), Singapore, 3-6 December 2007; pp. 407-412.

44. Wang, Y.; Li, W.; Lu, J. A new node voltage stability index based on local voltage phasors. Electr. Power Syst. Res. 2009, 79, 265-271. [CrossRef]

45. Sultana, U.; Khairuddin, A.B.; Aman, M.M.; Mokhtar, A.S.; Zareen, N. A review of optimum DG placement based on minimization of power losses and voltage stability enhancement of distribution system. Renew. Sustain. Energy Rev. 2016, 63, 363-378. [CrossRef]

46. Rahman, T.K.A.; Jasmon, G.B. A new technique for voltage stability analysis in a power system and improved load flow algorithm for distribution network. In Proceedings of the Proceedings 1995 International Conference on Energy Management and Power Delivery EMPD '95, Mankundu, West Bengal, India, 21-23 November 1995; Volume 2, pp. 714-719.

47. Verayiah, R.; Abidin, I.Z. A study on static voltage collapse proximity indicators. In Proceedings of the 2008 IEEE 2nd International Power and Energy Conference (PECon 2008), Johor Bahru, Malaysia, 1-3 December 2008; pp. 531-536.

48. Jasmon, G.B.; Lee, L.H.C.C. New contingency ranking technique incorporating a voltage stability criterion. IEE Proc. Gen. Transm. Distrib. IET 1993, 140, 87-90. [CrossRef]

49. Moghavvemi, M.; Faruque, O. Real-time contingency evaluation and ranking technique. IEE Proc. Gen. Transm. Distrib. IET 1998, 145, 517-524. [CrossRef]

50. Yazdanpanah-Goharrizi, A.; Asghari, R. A novel line stability index (NLSI) for voltage stability assessment of power systems. In Proceedings of the 7th WSEAS International Conference on Power Systems, Venice, Italy, 21-23 November 2007; pp. 164-167.

51. Musirin, I.; Rahman, T.K.A. On-line voltage stability based contingency ranking using fast voltage stability index (FVSI). In Proceedings of the IEEE/PES Transmission and Distribution Conference and Exhibition, Yokohama, Japan, 6-10 October 2002; Volume 2, pp. 1118-1123.

52. Sun, H.; Zhou, X.; Li, R. Accuracy analysis of static voltage stability indices based on power flow model. In Proceedings of the 2005 IEEE/PES Transmission and Distribution Conference and Exposition: Asia and Pacific, Dalian, China, 18 August 2005; pp. 1-7.

53. Nizam, M.; Mohamed, A.; Hussain, A. Performance evaluation of voltage stability indices for dynamic voltage collapse prediction. J. Appl. Sci. 2006, 6, 1104-1113.

54. Nai-shan, H.; Xu, T.; Liao, Q.; Lu, Z. The analysis of abundance index of voltage stability based circuit theory. Guangxi Electr. Power 2006, 2, 12-14. 
55. Chebbo, A.M.; Irving, M.R.; Sterling, M.J.H. Voltage collapse proximity indicator: behaviour and implications. IEE Proc. C Gener. Transm. Distrib. 1992, 139, 241-252. [CrossRef]

56. Cupelli, M.; Doig Cardet, C.; Monti, A. Voltage stability indices comparison on the IEEE-39 bus system using RTDS. In Proceedings of the 2012 IEEE International Conference on Power System Technology (POWERCON), Auckland, New Zealand, 23-26 October 2012; pp. 1-6.

57. Christine, E.D.C. Analysis on Voltage Stability Indices, 1st ed.; Polytechnic University of Catalonia: Barcelona, Spain, 2010.

58. Chiang, H.D.; Jean-Jumeau, R. Toward a practical performance index for predicting voltage collapse in electric power systems. IEEE Trans. Power Syst. 1995, 10, 584-592. [CrossRef]

59. De Souza, A.C.Z.; Caiiizares, C.A.; Quintana, V.H. New techniques to speed up voltage collations using tangent vectors. IEEE Trans. Power Syst. 1997, 12, 1380-1387. [CrossRef]

60. Berizzi, A.; Finazzi, P. First and second order methods for voltage collapse assessment and security enhancement. IEEE Trans. Power Syst. 1998, 13, 543-551. [CrossRef]

61. Furukakoi, M.; Adewuyi, O.B.; Danish, M.S.S.; Howlader, A.M.; Senjyu, T.; Funabashi, T. Critical Boundary Index (CBI) based on active and reactive power deviations. Int. J. Electr. Power Energy Syst. 2018, 100, 50-57. [CrossRef]

62. Ratra, S.; Tiwari, R.; Niazi, K.R. Voltage stability assessment in power systems using line voltage stability index. Comput. Electr. Eng. 2018, 1, 1-13. [CrossRef]

63. Danish, M.S.S.; Yona, A.; Senjyu, T. A Review of Voltage Stability Assessment Techniques with an Improved Voltage Stability Indicator. Int. J. Emerg. Electr. Power Syst. 2015, 16, 107-115. [CrossRef]

64. Sagara, M.; Furukakoi, M.; Senjyu, T.; Danish, M.S.S.; Funabashi, T. Voltage stability improvement to power systems with energy storage systems. In Proceedings of the 17th International Conference on Harmonics and Quality of Power (ICHQP 2016), Belo Horizonte, Brazil, 16-19 October 2016; pp. 7-10.

65. Berizzi, A.; Bresesti, P.; Marannino, P.; Granelli, G.P.; Montagna, M. System-area operating margin assessment and security enhancement against voltage collapse. IEEE Trans. Power Syst. 1996, 11, 1451-1462. [CrossRef]

66. Massucco, S.; Grillo, S.; Pitto, A.; Silvestro, F. Evaluation of some indices for voltage stability assessment. In Proceedings of the 2009 IEEE Bucharest PowerTech, Bucharest, Romania, 28 June-2 July 2009; pp. 1-8.

67. Taylor, C.W. Criteria and Countermeasures for Voltage Collaps; CIGRE TF38-02-12; CIGRE: Paris, France, 1995.

68. Julian, D.E.; Schulz, R.P.; Vu, K.T.; Quaintance, W.H.; Bhatt, N.B.; Novosel, D. Quantifying proximity to voltage collapse using the Voltage Instability Predictor (VIP). In Proceedings of the 2000 Power Engineering Society Summer Meeting (Cat. No.00CH37134), Seattle, WA, USA, 16-20 July 2000; Volume 2, pp. 931-936.

69. Milǒsević, B.; Begović, M. Voltage-stability protection and control using a wide-area network of phasor measurements. IEEE Trans. Power Syst. 2003, 18, 121-127. [CrossRef]

70. Li, W.; Wang, Y.; Chen, T. Investigation on the Thevenin equivalent parameters for online estimation of maximum power transfer limits. IET Gener. Transm. Distrib. 2010, 4, 1180-1187. [CrossRef]

71. Gong, Y.; Schulz, N.; Guzmán, A. Synchrophasor-based real-time voltage stability index. In Proceedings of the 2006 IEEE PES Power Systems Conference and Exposition, Atlanta, GA, USA, 29 October-1 November 2006; pp. 1029-1036.

72. Glavic, M.; Cutsem, T.V. Wide-area detection of voltage instability from synchronized measurements. Part 1 : Principle. IEEE Trans. Power Syst. 2009, 24, 1408-1416. [CrossRef]

73. Zeng, Y.G.; Berizzi, G.; Marannino, P. Voltage stability analysis considering dynamic load model. In Proceedings of the International Conference on Advances in Power System Control, Operation and Management, Hong Kong, China, 11-14 November 1997; IET: Hong Kong, China, 1997; pp. 396-401.

(C) 2019 by the authors. Licensee MDPI, Basel, Switzerland. This article is an open access article distributed under the terms and conditions of the Creative Commons Attribution (CC BY) license (http://creativecommons.org/licenses/by/4.0/). 